\title{
Histopathological Studies of Seed Infected with Seed Borne Fungi
}

\author{
A. R. Gulhane, Shilpa V. Khambalkar* and G. K. Giri \\ Sorghum Research Unit, Dr. PDKV, Akola, Maharashtra, India \\ *Corresponding author
}

\section{A B S T R A C T}

\begin{tabular}{|l|}
\hline Ke y w or d s \\
$\begin{array}{l}\text { Curvularia lunata, } \\
\text { Bipolaris sorghicola and } \\
\text { B. sorokiniana }\end{array}$ \\
\hline Article Info \\
\hline Accepted: \\
28 March 2018 \\
Available Online: \\
10 July 2018 \\
\hline
\end{tabular}

\section{Introduction}

Rice, wheat, sorghum and pearl millet is an important crop in India. Seed borne diseases cause economic losses to our crop. The infected seed may fail to germinate, transmit diseases from seed to seedling and from seedling to growing plant.

Brown to black discoloration of wheat were analysed to identified the Drechslera spp. associated with black point disease. The fungi the embryos endosperm and seed coats of the Kernels (Ozer, 2005). The C. lunata is one of the major grain mould of sorghum, the fungus causes black discoloration of seed, degradation of endosperm and infect the embryo. Histologically sorghum seed consist and pericarp seed coat, endosperm and embryo (Deshmukh and Raut, 1993; Girish et al., 2004; Singh and Agrawal, 1989). B. oryzae and $C$. oryzae infected all parts of seed coat embryo, black dots and brown spot of fungus present on seed coat. Infection of $C$. oryzae and average percent of incidence was $10 \%$ from seed coat (Pandy et al., 2000; Ibrahim and Abo-Ei-Dahab, 2014; Somsiri sangchote and Van, 2006).

Histology of brown discolor seed to confirm the presence of mycelium of $C$. penniseti in different part of seed mycelium was confirmed to pericarp and Endosperm and embryo of pearl millet seed (Singh and Singh, 2004; Singh et al., 2008).

The present studies were conducted to determine the location of seed borne fungi and their seed transmission in different seed of sorghum, wheat, pearl millet and rice. 


\section{Materials and Methods}

Fifty seed of sorghum, wheat, paddy and pearl millet from infected seed lot having characteristics symptoms of seed borne fungi were boiled in distilled water for $30 \mathrm{~min}$ at $60^{\circ} \mathrm{C}$.

Later, seeds were soaked in $70 \%$ ethanol for 48 hours. The seed become soft and was ready to give a cut.

Seed of sorghum, wheat, paddy and pearl millet were cut transversely into two pieces at the center of seed to ensure better dehydration, infiltration and embedding.

The fixed seeds were dehydrated through acetone I, II, III, IV series for 40 minutes per treatment and benzene I, II for 20 $\mathrm{min} /$ treatment and infiltrated using paraffin wax at $52^{\circ} \mathrm{C}$ for 2 hours. The solid paraffin wax was liquidified and poured in the blocks, cut seeds were placed at the centre of per block, so that the seeds were embedded in the solid wax and the blocks were cooled overnight. Next day, blocks were cut into squares.

The blocks were used for serial microtome sections of 7-15 $\mu \mathrm{m}$ thickness by using hand rotary microtome. The ribbon of sections were uplifted, kept floating in water bath having $40^{\circ} \mathrm{C}$ temperature to deparaffinise the wax and the sections were lifted on the slides. The slides were heated on spirit lamp to make ready for staining and mounted in DPX.

\section{Results and Discussion}

Histopathology of infected seed and colonization of major seed borne fungi viz., Curvularia, Bipolaris and Drechslera in sorghum, wheat, paddy and pearl millet seeds were carried out with the help of hand rotary microtome.
Location of seed borne fungi in seed component

\section{Curvularia lunata}

Microphotograph (Plate 1a, b) of sorghum seed section showed distribution of mycelial fragments of Curvularia lunata in seed coat and floury endosperm. Microtomy section of wheat seed revealed the presence of brown colored thick mycelial fragments of Curvularia lunata in endosperm and embryonic region (Plate 1c). It was also similarly seen that (Plate 1d) the brown / black colored thick mycelial fragments of Curvularia lunata present in embryo region of pearl millet seed. Mycelium of Curvularia lunata was also noticed in the pericarp region (Plate 1e) of paddy seed.

Thus, it can be concluded that the Curvularia lunata were widely distributed in various components of the seed including seed coat, endosperm, pericarp and embryonic region.

\section{Bipolaris sorghicola}

The microtomy sections of sorghum and pearl millet seed indicates the presence of brown colored thick mycelial fragments of Bipolaris sorghicola in pericarp and embryo region of sorghum and pearl millet seed, respectively (Plate 2a, b).

\section{Bipolaris sorokiniana}

The brown colored thick mycelial fragments of Bipolaris sorokiniana was observed in pericarp region (Plate 3 ) of wheat seed.

Results of histopathology of Curvularia and Bipolaris infected seed showed the distribution of fungi in the pericarp, seed coat, endosperm and embryo. The septate, brown, thick and knotty mycelium invaded the various seed parts. 


\section{Staining procedure of slides}

\begin{tabular}{|l|l|c|}
\hline Sr. No. & \multicolumn{1}{|c|}{ Staining procedure steps } & Time required (min) \\
\hline 1 & Xylene -I (dip) & 3 \\
\hline 2 & Xylene -II (dip) & 3 \\
\hline 3 & Absolute alcohol (100\%) I & 3 \\
\hline 4 & Absolute alcohol (100\%) II & 3 \\
\hline 5 & Rectified spirit I & 3 \\
\hline 6 & Rectified spirit II & 3 \\
\hline 8 & Washing under tap water & 5 \\
\hline 9 & Cotton blue stain & 5 \\
\hline 10 & Washing under tap water & 10 \\
\hline 11 & Blotting and drying & 10 \\
\hline 12 & Carbol fuschin & $3-5$ \\
\hline 13 & Rectified spirit & 1 dip \\
\hline 14 & Rectified spirit & 1 dip \\
\hline 15 & Absolute alcohol & 2 dip \\
\hline 16 & Absolute alcohol & 3 dip \\
\hline 17 & Xylene - I & 3 \\
\hline 18 & Xylene - II & 3 \\
\hline 19 & Mounting in DPX & \\
\hline
\end{tabular}

Plate.1 Histopathology of Curvularia sp. in pearl millet, sorghum, wheat and paddy seed

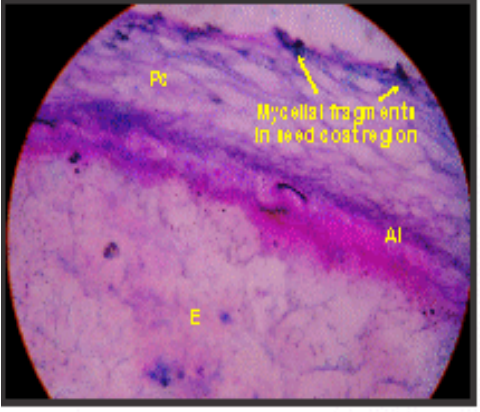

a) Infedion of Curvilarialunata in sorghu m seed

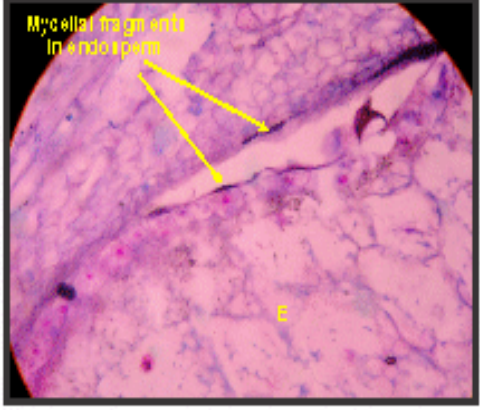

b) Infection of Curvularia lunata in sorghu m seed

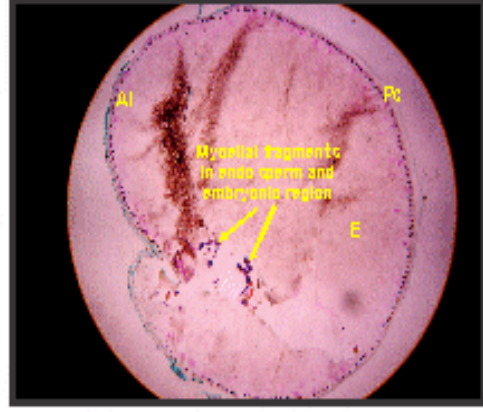

c) Infection of Curviarialunata in whest seed

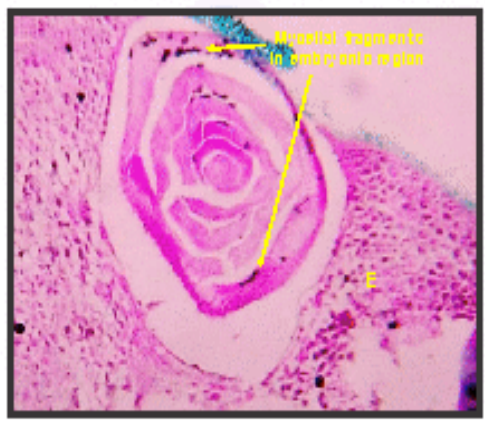

d) Infection of Curvularialunata in pearl millet seed

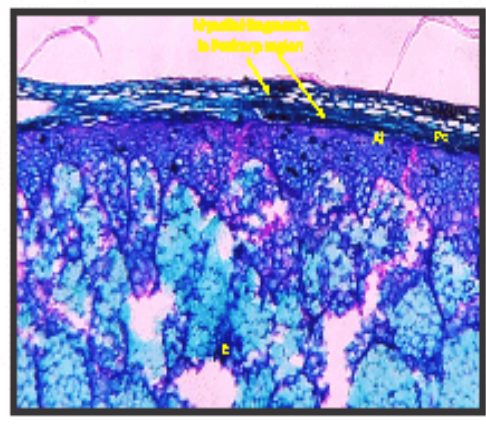

e) Infection of Curvularia lunata in paddy seed

Pc - Pericarp, Al - Alurone layer, E - Endosperm 
Plate.2 Histopathology of Bipolaris spp. in pearl millet, sorghum and wheat seed

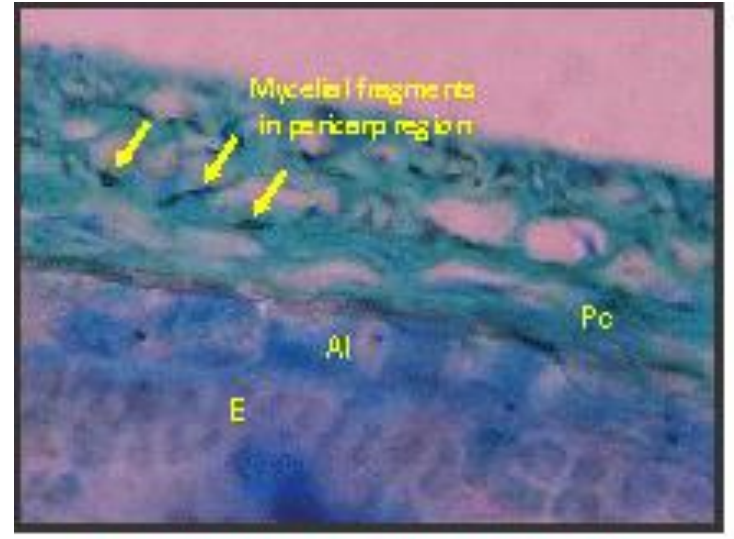

a) Infection of Bipolaris sorghicola in pearl millet seed

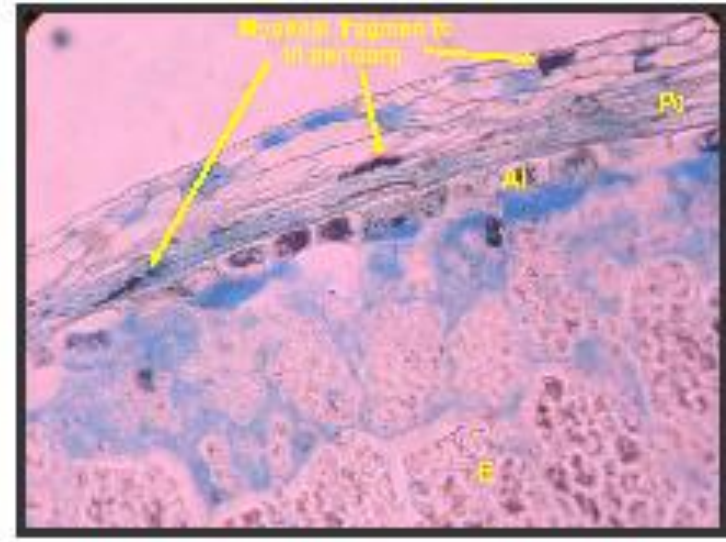

b) Infection of Bipolaris sorghicola in sorghu m seed

Plate.3 Histopathology of Bipolaris spp. in pearl millet, sorghum and wheat seed
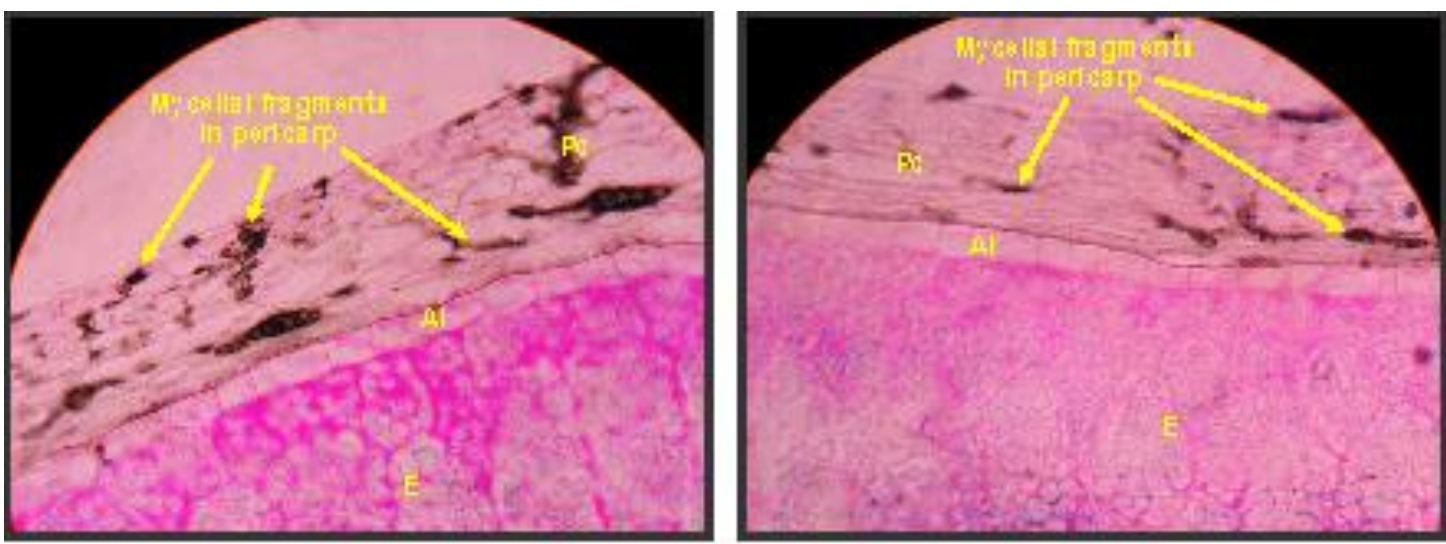

c) Infection of Bipolaris sorokiniana in whest seed

The fungi were found colonize in seed coat, pericarp, and endosperm and embryo region. Thus, histopathological studies revealed that, Curvularia lunata, Bipolaris sorokiniana and Bipolaris sorghicola infect the seed and colonize in various seed tissues and damage the embryo and affect seed viability. These findings are similar to those of Caster (1977) and Caster and Frederiksen (1980) who recorded the infection of Curvularia lunata in overy wall, pericarp, endosperm and embryonic tissue of sorghum seed. The presence of Curvularia lunata and Curvularia oryzae in all part of seed including embryo, seed coat and endosperm of sorghum and rice seed have also been reported by Deshmukh and Raut (1993) and Pandey et al., (2000), respectively. Thus, confirms the results of present investigation.

In the present investigation, the colonization of Curvularia lunata was observed in the embryonic region of wheat seed. Observation on same line have been reported by Khulbe et al., (2011) in the form of light brown and dark brown to black discoloration due to Bipolaris sorokiniana and Curvularia lunata respectively in the embryonic region of wheat seed, which supports the findings of present investigations. 
Histopathology of Curvularia and Bipolaris infected seed showed the distribution of fungi in the pericarp, seed coat, endosperm and embryo. The septate, brown, thick and knotty mycelium invaded the various seed parts. The fungi were found colonize in seed coat, pericarp, and endosperm and embryo region. Thus, histopathological studies revealed that, Curvularia lunata, Bipolaris sorokiniana and Bipolaris sorghicola infect the seed, colonize in various seed tissues and damage the embryo and affect seed viability.

\section{References}

Aggarwal, R., S. Das, M. Jahani and D.V. Singh, 2008. Histopathology of spot blotch disease of wheat caused by Bipolaris sorokiniana (Teleomorph: Cochliobolus sativus). Acta Phytopathologicast Entomologica Hungarica. 43(1): 23-30.

Castor, L.L. and R.A. Frederiksen, 1980. Fusarium and Curvularia grain mold in Texas. In Sorghum Diseases A World Review: Proc. of the International Workshop on Sorghum Diseases 11 to 15 Dec. 1978. ICRISAT, Hyderabad, India. pp 93-102.

Castor, L.L. 1981. Grain mould histopathology, damage, assessment and resistance screening within Sorghum bicolor (L.) Moench. *Lines. Ph.D. thesis, Texas A and M. Univ. College Station Texas, U.S.A. pp 192.

Deshmukh, R.N. and J.G. Raut, 1993. Sites of Curvularia lunata infection in sorghum seed. Indian Phytopathology. pp 251.

Girish, A.G., S. Deepti, V.P. Rao and R.P. Thakur, 2004. Detection of seed borne grain mold fungi in sorghum and their control with fungicidal seed treatment. ISMN, 45: 31-33.
Ibrahim, E.A.M. and M.S. Abo El-Dahab, 2014. Seed discoloration and their effect on seedlings growth of Egyptian hybrid rice. Research Journal of Seed Science. 7: 63-74.

Kumar Manoj and V.K. Agarwal, 1998. Location of seed borne fungi associated with discolored maize seeds. Indian Phytopath. 51(3): 247-250.

Ozer, Nuray, 2005. Determination of fungi responsible for black point in bread wheat and effects of the disease on emergence and seedling vigour. Trakya Univ. J. Sci. 6(1): $35-40$.

Pandey Vachspati, V.K. Agarwal and M.P. Pandey, 2000. Location and seed transmission of fungi in discoloured seeds of hybrid rice. Indian Phytopath. 53(1): 45-49.

Singh Archana, R. L. Meena and C. Chattopadhyaya, 2008. Location and Transmission of Curvularia penniseti in Pearl Millet. J. Mycol. PI. Path. 38(2): 185188

Singh*, D.P. and V.K. Agrawal, 1989. Effect of different degrees of grain molds infection on yield and quality of sorghum seed. Indian J. Plant Pathol. 7(2): 103-108.

Singh, Ruby and Tribhuwan Singh, 2004. Seed infection and transmission of Drechslera halodes in pearl mille. J. Mycol. Pl. Pathol. 34(2): 264-268.

Somsiri Sangchote and Van Ba, Vu, 2006. Seed borne and transmission of Bipolaris oryzae the causal pathogen of brown spot of rice. Kaseart J. 40: 35ts3-360.

Yago, Jonar I, Jae-Hwan Roh, Soon-do Bae, Young-Nam Yoon, Hyun-Ju Kim and Minhee Nam, 2011. The effect of seed-borne mycoflora from sorghum and foxtail millet seeds on germination and disease transmission. Mycobiology, 39(3): 206-218.

\section{How to cite this article:}

Gulhane, A. R., Shilpa V. Khambalkar and Giri, G. K. 2018. Histopathological Studies of Seed Infected with Seed Borne Fungi. Int.J.Curr.Microbiol.App.Sci. 7(04): 4108-4112. doi: https://doi.org/10.20546/ijcmas.2018.707.478 